Principal Davis's little book consists of two parts. The first, devoted to plants, gives an admirable résumé of their being and well-being, their varieties and adaptations. The second treats in systematic fashion the chief groups of animals, and, though less "biological," is well arranged and packed with information. The illustrations throughout are most attractive, and the plan of the text well designed. For schools the book is certain to be found useful, and the only faults we have to find with it are the attempt to explain everything and the absence of any attempt to give practical directions for the simplest experiment. The first is certainly a serious mistake. The too ready application of the magic word "protection" in regard to colouring, for example, is frequently unjustified, and the bald statement, e.g., that birds are derived from reptiles that rose on aëroplanes, is at least a daring one when its speculative nature is not hinted at. Phylogenetic speculation should be rigorously excluded from elementary teaching.

The absence of experimental advice is a too common drawback to books of this kind, and yet perhaps no method is equal to this one in value. With animals there is always a difficulty in suggesting an experiment that has not an unnatural or even a cruel look, but plants are made for experiment, and a training in that branch of work is one that can be effected cheaply and conveniently. These defects do not, however, prevent this little book from being a fund of attractive information on both animals and plants. The subject-matter is highly compressed, and teachers will find that a single paragraph has to be expanded and illustrated before it can be properly grasped by their pupils. Such compactness is, however, inevitable in a work of such small size and wide compass.

\section{INTERNATIONAL CHART OF THE}

\section{HEA VENS.}

THE permanent committee of the Astrographic Congress of 1887 will meet at the Paris Observatory, April ig to 24 . Our readers will remember that the great international undertaking-the Carte du Ciel-was inaugurated at a congress held at Paris in I887. No astronomer who attended the meeting can forget the man whose name will ever be associated with that work-Admiral Mouchez, then director of the Paris Observatory. But for his earnest and sympathetic character and genial influence it is doubtful if this great work could have been launched at all; it certainly could not have been so with the same prospect of success without his tactful and energetic cooperation.

At that congress a scheme was prepared and a permanent committee appointed to carry the work into execution. The committee in question consisted of eleven members, selected by vote, together with the directors of observatories cooperating in the work whose names did not appear in the original list. This committee met at intervals of from two to four years at Paris until the year 1900 inclusive, but since that time no further meeting of the permanent committee has taken place, and we shall see presently how urgent is the need for the coming meeting.

Broadly speaking, the programme entrusted to the committee was as follows :-

(r) To construct charts of the entire sky, each map measuring $2^{\circ} \times 2^{\circ}$, and containing all stars to the thirteenth magnitude.

(2) To catalogue the exact positions and magnitudes of all stars to the eleventh magnitude.

At first the chart appeared, even to some astronomers, to be the more important object to be realised, but there has been a growing conviction that, for the broad fundamenta of astronomy, the catalogue, though by far the more laborious, is infinitely the more important of the two objects.

The chart, it is true, preserves a permanent record of the state of the sky for a mean epoch about I9oo, to which reference can be made, as occasion may arise, in connection with variable stars and the appearance of new stars, and, after special measures, it will yield the places of stars fainter than the eleventh magnitude which may be suspected of large proper motion, \&c.

But, with the completion of the catalogue, astronomers will be provided with absolute places of all the stars down to the eleventh magnitude, and this will enable them, when the work has been repeated after a sufficient interval, to derive the proper motions of all stars to the eleventh magnitude in the most simple and direct manner, and so to investigate such problems as the precession, the solar motion in space, star-drift, \&c., and to discuss the general problems of sidereal astronomy with a completeness unattainable in any other way.

By the complete execution of our present programme we lay upon astronomers of the future the moral compulsion to execute a similar work, say, one hundred years hence, and, in addition, to derive from the three or four millions of proper motions so obtained the broad cosmical conclusions which must follow from the proper discussion of these motions.

This, surely, is a large enough task to bequeath to futurity-a noble bequest indeed if it be left in the complete, permanent and accessible form of a printed catalogue of positions and magnitudes. To leave it in any other form would be to endanger the permanent value of our work by throwing such an undue share of labour upon our successors as almost to justify them in refusing to utilise what we have done.

The work of the chart and of the catalogue was originally divided amongst sixteen observatories, and naturally has proceeded at different rates in different observatories according to their opportunities, the varied energy of their directors, and the means at their disposal. Practically the work has now continued for nearly twenty years, but, of course, a good deal of time was lost at first in the construction of instruments and in experimental research before definite routine work was commenced.

But whilst some of the observatories have nearly completed their share of the work, others are far behind, and it will be an important duty of the present meeting to inquire into the progress of each zone, to divide up the unexecuted work amongst the more active observatories, and to take such other steps as are necessary to bring the whole to an early and satisfactory completion.

In a circular letter addressed to the directors of the cooperating observatories and to others invited to attend the present meeting, M. Baillaud, director of the Paris Observatory, and president of the permanent committee, makes the following requests, viz. :- -

(a) That each observatory which, up to the present time, has cooperated in the work, shall prepare a report showing the amount of work done, not only in taking the plates, but in the measurement, reduction, and publication of the results.

$(\beta)$ That those astronomers who find themselves in a position to aid in the completion of zones which have fallen into arrear either in the matter of taking the plates or in their measurement and reduction, should intimate their readiness to assist in the work.

In entering into the whole question of the present state of the work, and taking such farther steps as No. 2059, VOL. 8o] 
shall ensure its completion, the present meeting of the permanent committee has a most practical and important duty before it. But it has still further matters of interest and importance to deal with.

First, as regards the chart and catalogue, it must be remembered that to a great extent the sixteen observatories have been working independently, and it is impossible that, in existing circumstances, these results can be entirely homogeneous.

For example, at some observatories the diameters of the star-discs have been measured; at others, the magnitudes have been estimated by comparison with sets of photographed images assumed to represent stars of known magnitude. It will be the business of the "Magnitudes Committee" to devise effective means for reducing these measures of diameter and miscellaneous estimates to a uniform and absolute system of magnitudes. Another committee will deal with the systematic errors which have been found to exist in the coordinates of star-images measured in certain series of plates. In some cases these errors depend on the magnitude of the star, in others on its distance and position angle from the centre ot the plate. The optical committee will have to trace, so far as possible, the origin of these errors, and devise means for eliminating their effects from the final results.

The coordinates of the star-images measured on the plates are of no value for the purposes of fundamental astronomy unless the system of the coordinates of each plate is referred to a number of stars the absolute positions of which on the sphere are known. In the case of some of the zones the places of the reference stars depend on meridian observations, few in number and made a considerable number of years ago; in other cases they depend on recent but only locally observed zones. It is essential that not only should adequate provision be made for proper meridian observation of the zones, but also for their coordination to a common system on the plan so far carried out by Dr. Kastner at Bonn. The arrangement of this part of the work will rest with the fundamental stars committee.

At the last meeting of the permanent committee in 1900 , a good deal of time was given to consideration of the steps to be taken for the observation of the then recently discovered planet Eros, at its opposition at the end of I9oo. The bureau of the committee has published a large number of the observations of Eros that were secured at the opposition of 1900 , as well as the results of meridian and photographic observations of the comparison stars, and an accurate ephemeris of the planet for that opposition. The unique characteristics of the orbit of Eros present conditions which are exceptionally favourable for researches of extraordinary astronomical interest and importance, viz. for the trigonometrical determination of the solar parallax and mass of the moon, and for the dynamical determination of the mass of the earth by the perturbations which it produces in the motion of Eros. In I 900 Eros approached the earth within one-third of the earth's mean distance from the sun, but at the opposition of I93 I it will approach the earth within half that distance, viz. within one-sixth part of the earth's mean distance from the sun. It is not, even now, too soon to begin preparation for this unique opportunity, and accordingly an Eros committee will be appointed for the following purposes:-

(a) $\mathrm{T} J$ receive reports on the actual state of the reducductions of the past observations of Eros, and to prepare a report upon them.

(b) To take steps for the preparation of an approximate ephemeris of Eros at the opposition of I93 I of sufficient accuracy to permit the selection of the most suitable comparison stars.

(c) To discuss the best methods of observing the opposition in question, especially with a view to avoid systematic error in the final results.

(d) To discuss the basis of the choice of comparison stars, and how to ensure their proper observation.

(e) To devise means for the regular observation of Eros from this time forward in order to perfect the ephemeris that will be finally employed in the definitive reduction of the observations of I93I, that is to say, for the direct determination of the solar parallax and mass of the moon, and also for the ultimate determination of the mass of the earth by means of the perturbations which it produces in the motion of Eros.

There can be no doubt that all these objects can only be attained by international cooperation, and that they furnish ample material for an interesting and important meeting. The following astronomers have accepted M. Baillaud's invitation on the part of the French Government to be present on the occasion : $\rightarrow$

Prof. Andoyer, Paris; Ch. André, Lyon; M. Angot, Paris; T. de Azcarate, San Fernando; O. Backlund, Pulkova; B. Baillaud, Paris; J. Baillaud, Paris; H. G. van de Sande Bakhuyzen, Leyden; Le Général Bassot, Nice; de la Baume Pluvinel, Paris; M. Bayet, Paris G. Bigourdan, Paris; G. Boccardi, Turin; Prince Roland Bonaparte; F. Boquet, Paris; H. Bourget, Marseilles; Sir W. H. M. Christie, Greenwich; W. E. Cooke, Perth; W. Australia; M. Cosserat, Toulouse; M. Deslandres, Meudon; A. Donner, Helsingfors; F. W. Dyson, Edinburgh; John Franklin-Adams, London; A. Gaillot, Paris; P. Gautier; Sir David Gill, London; M. Gonnessiat, Algiers; G. E. Hale, Mount Wilson; M. Hamy, Paris A. R. Hinks, Cambridge; S. S. Hough, Cape Town; Fernand Jacobs, Brussels; J. C. Kapteyn, Groningen; E. B. Knobel, London; M. Kromm, Bordeaux ; F. Küstner, Bonn; Le R. P. Laîs, Rome; I. Lagarde, Paris; A. Lebeuf, Besançon; G. Lecointe, Brussels; G. Leveau, Paris; M. Lumière, Lyon; Major P. A. MacMahon, London; J. Palisa, Vienna; C. D. Perrine, Mount Hamilton; L. Picart, Bordeaux; A. A. Rambaut, Oxford H. Renan, Paris; A. Ricco, Catania; J. Scheiner, Potsdam; M. Stéphan, Marseilles; E. Strömgren, Copenhagen ; H. H. Turner, Oxford; F. Valle, Tacubaya; M. Verschaffel, Abbadia; W. Zurhellen, Bonn.

\section{DR. ARTHUR GAMGEE, F.R.S.}

HIS numerous friends and fellow-workers in 1 science, both in this country and abroad, will hear with deep regret of the unexpected death of Dr. Arthur Gamgee, in Paris, on March 29. He was in his sixty-eighth year, and though not a young man was in full possession of an exception. ally endowed intellect which was ever urging him on in the path of research. Throughout a somewhat unsettled life his enthusiasm for research never waned from the time of his early student days, when he followed his natural leanings towards original physiological work, to which his exact knowledge of physics and chemistry was to be applied with a success that gained for him a wide and well-deserved reputation.

To many of the younger physiologists Dr. Gamgee was personally unknown. He was born in $184 \mathrm{I}$, in Edinburgh, a younger son of Joseph Gamgee, a distinguished veterinary surgeon and pathologist, whose work, particularly that on rinderpest, was well known in England and on the Continent. An elder brother, Joseph Sampson Gamgee, long connected with the general hospital in Birmingham, was a man of great mental gifts and remarkable personality, who made a name for himself in his profession, and will be remembered for the introduction of improved methods in the treatment of wounds 